\title{
Assessment of Soil Erosion and Its Impact on Agricultural Productivity by Using the RMMF Model and Local Perception: A Case Study of Rangun Watershed of Mid-Hills, Nepal
}

\author{
Dinesh Bhandari $\mathbb{D}^{1},{ }^{1}$ Rajeev Joshi $\mathbb{D}^{2,3}$ Raju Raj Regmi ${ }^{2},{ }^{1}$ and Nripesh Awasthi ${ }^{4}{ }^{4}$ \\ ${ }^{1}$ Tribhuvan University, Institute of Forestry, Pokhara Campus, Post Box No.: 43, Hariyo Kharka-15, Pokhara, Gandaki, Nepal \\ ${ }^{2}$ Faculty of Forestry, Amity Global Education (Lord Buddha College), CTEVT, Tokha-11, Kathmandu 44600, Nepal \\ ${ }^{3}$ Forest Research Institute (Deemed to be) University, Dehradun 248195, Uttarakhand, India \\ ${ }^{4}$ Ministry of Industry, Tourism, Forest and Environment, Kailali, Sudurpaschim, Nepal
}

Correspondence should be addressed to Rajeev Joshi; joshi.rajeev20@gmail.com

Received 13 June 2021; Accepted 6 August 2021; Published 13 August 2021

Academic Editor: Durgesh Jaiswal

Copyright (c) 2021 Dinesh Bhandari et al. This is an open access article distributed under the Creative Commons Attribution License, which permits unrestricted use, distribution, and reproduction in any medium, provided the original work is properly cited.

\begin{abstract}
Soil erosion is a major concern for the environment and natural resources leading to a serious threat to agricultural productivity and one of the major causes of land degradation in the mid-hills region of Nepal. An accurate assessment of soil erosion is needed to reduce the problem of soil loss in highly fragile mountainous areas. The present study aimed to assess spatial soil loss rate and identified risk areas and their perceived impact on agricultural productivity by using the Revised Morgan-Morgan-Finney (RMMF) model and social survey in the Rangun watershed of Dadeldhura district, Nepal. Soil erosion was assessed by using data on soil, digital elevation model, rainfall, land use, and land cover visually interpreted from multitemporal satellite images, and ILWIS 3.3 academic software was used to perform the model. A household questionnaire survey $(n=120)$ and focus group discussion $(n=2)$ in identified risk areas were carried out to understand the people's perception towards soil erosion and its impact on agricultural productivity. The predicted average soil erosions from the forest, agriculture, and barren land were $2.7 \mathrm{t} \mathrm{ha}^{-1} \mathrm{yr}^{-1}, 53.73 \mathrm{t} \mathrm{ha}^{-1} \mathrm{yr}^{-1}$, and $462.59 \mathrm{t} \mathrm{ha}^{-1} \mathrm{yr}^{-1}$, respectively. The erosion risk area under very low to low, moderate to moderately high, and high to very high covers $92.32 \%, 4.96 \%$, and $2.73 \%$, respectively. It indicates that the rate of soil erosion was lower in forest areas, whereas it was higher in the barren land. The cropped area of the watershed has been reduced by $2.96 \mathrm{ha}^{-1} \mathrm{yr}^{-1}$, and productivity has been decreased by $0.238 \mathrm{t} \mathrm{ha}^{-1} \mathrm{yr}^{-1}$. The impacts such as removal of topsoil (weighted mean $=4.19$ ) and gully formation (weighted mean $=3.56$ ) were the highest perceived factors causing productivity decline due to erosion. People perceived the impact of erosion in agricultural productivity differently ( ${ }^{*}$ significant at $P \leq 0.05$ ). The study concluded that, comparatively, barren and agricultural lands seem more susceptible to erosion, so the long-term conservation and management investment in susceptible areas for restoration, protection, and socioeconomic support contribute significantly to land rehabilitation in the Rangun watershed.
\end{abstract}

\section{Introduction}

Land resource degradation in the Himalayan region occurs mainly due to landslide, mudslide, man-made terraces, soil loss from steep slope, and decline of forest/pasture areas $[1,2]$. Degradation is broadly natural and anthropogenic [3]. In general, soil erosion, flood, and landslides caused by torrential rain, forest fire, slash and burn cultivation, inappropriate agriculture practices, uncontrolled grazing and overgrazing, encroachment and unplanned settlements, and so forth are the common problems of the Churia hills [4]. Annually, nearly 24 million tons of soil are washed away from the country [5]. About $34 \%$ of the agricultural land in Nepal suffers from water erosion, mostly through the sheet and rill erosion $[6,7]$.

Soil erosion is defined as the natural phenomenon in which removal and transportation of soil material occur mainly through the action of erosive agents such as water, 
wind, gravity, and human disturbances [8,9]. It is the biggest threat to soil fertility and productivity, mostly due to human disturbances $[10,11]$. Soil erosion causes negative impacts on the environment and the economy, removes organic matter and important nutrients, and prevents vegetation growth, which negatively affects overall biodiversity $[12,13]$. The loss of soil fertility in arable lands and decline in the quality of the soil resources are the major consequences of soil erosion [14, 15]. The soil erosion process alters the physical, chemical, and biological characteristics of soil, which creates a reduction in agricultural productivity and arable land size and causes facing the problem of food scarcity, especially in the context of growing world population [16-19]. Soil loss from agricultural land leads to the decreased crop production, potential damaged drainage networks, and lower water quality surface [20, 21]. Soil erosion created severe problems for human sustainability on agricultural productivity, water quality, hydrological system, soil fertility, and environments [22, 23].

To estimate the soil erosion and suggest an appropriate management plan, several models such as Universal Soil Loss Equation (USLE), Revised Universal Soil Loss Equation (RUSLE), Water Erosion Prediction Project (WEPP), Morgan-Morgan-Finney (MMF), Soil Loss Estimation Model for Southern Africa (SLEMSA), and Soil and Water Assessment Tools (SWAT) have been developed and used data inputs generated through GIS [24]. Some models, applicable to a particular area, may not be directly applicable to other areas as they were designed for specific applications [25]. Among these models, the most practical method for assessing soil erosion is USLE, but it has many limitations for application at catchment scale [26]. On the other hand, process-based erosion models have limitations on applicability due to intensive data and computation requirements [27]. The application of process-based models requires large amount of data that may not be available mainly in developing regions [28]. In this study, Revised Morgan-Morgan-Finney (RMMF) model was used to estimate the annual soil erosion rate. This model was selected because of its simplicity, flexibility, and having a stronger physical base compared to USLE. In addition, it is a physically based empirical model and requires a less amount of data as compared to most of the other erosion predictive models. To estimate soil erosion, this model involves two phases, that is, water phase and sediment phase [29].

Limited researchers have undertaken studies related to erosion issues [1, 28, 30]; some attention with regard to erosion modeling is essential considering the inaccessibility of the mountainous areas. The present study aims to evaluate the applicability of an erosion model in mountainous region. This study will help to demonstrate the extent of soil erosion in different land types and consequences observed on agriculture productivity could provide valuable information to formulate further strategy and action to control soil erosion and land productivity improvement at the local scale and also provide important information for land users and planners which would be a basis for decision-making for the effective management of the land resource. The study was aimed to derive and assess the spatial distribution of hydrophysical parameters developed using ILWIS Academic 3.3 and apply them to the RMMF model for assessing spatial soil loss rate and identified erosion risk areas of the Rangun watershed.

The findings and the outputs are very useful for the future implementation of erosion hazards management activities in the watershed areas, which is essential to protect and provide multiple benefits to society and regulation of the environment. This baseline research will also be helpful for further continuation study.

\section{Methods and Methodology}

2.1. Study Area. The study area, namely, Rangun watershed, is located in the subtropical to the temperate region of FarWestern Development Region, Nepal (Figure 1). The watershed has an area of $450.80 \mathrm{sq}$. $\mathrm{km}$ and the outlet of this watershed drains into the Mahakali river basin. The annual average summer temperature of the study area is $31^{\circ} \mathrm{C}$ and the average annual winter temperature is $20^{\circ} \mathrm{C}$. At higher elevations, the average summer temperature is $23^{\circ} \mathrm{C}$ and the average winter temperature is $8^{\circ} \mathrm{C}$ with extreme values of $3^{\circ} \mathrm{C}$ in January (Dadeldhura station). Annual precipitation also varies according to elevation changes, from $598 \mathrm{~mm}$ at the low altitudes (Jogbuda, 350 masl) to $1998 \mathrm{~mm}$ at higher altitudes (Hagulte, 2124 masl), where average annual rainfall is less than the overall average of the country. The maximum rainfall records were during the months of June to September. Land use is predominantly covered by forest and arable, being the major crop along with different proportions of pasture land and scattered patches of trees, bushes, and shrubs. The major rock types are mudstones, shale, sandstones, siltstones, and conglomerates.

2.2. Research Approach. In this study, the research approach consists of five main steps. These are (i) identification of hydrophysical inputs parameters of RMMF model, (ii) field survey and informal discussion to verify the LULC Map and collection of metrological data of the study area, (iii) application of empirical relations to calculate intermediate RMMF model inputs described by [31], (iv) application of RMMF model in ILWIS Academic 3.3 while estimating spatially distributed erosion outputs such as soil loss rate and erosion risk maps, and (v) conducting field observation and households survey through questionnaire and focus group discussion (FGD) to address the impact of erosion on crop productivity.

2.3. RMMF Model Input Parameters. Model inputs parameters include rainfall $(\mathrm{mm})$, land use, digital elevation model (DEM) for slope map derivation, soil texture, soil moisture content at field capacity $\left(\% w \cdot w^{-1}\right)$, soil detachability index $\left(\mathrm{g} \mathrm{J}^{-1}\right)$, bulk density of soil $\left(\mathrm{Mg} \mathrm{m}^{-3}\right)$, the cohesion of soil surface $(\mathrm{kPa})$, soil moisture storage capacity $(R c)$, effective hydrological topsoil depth (EHD), and the ratio of actual to potential evapotranspiration $\left(E t / E_{0}\right)$ [32]. The various input data were gathered from different sources such as empirical relations, field determination, and literatures. Meteorological 


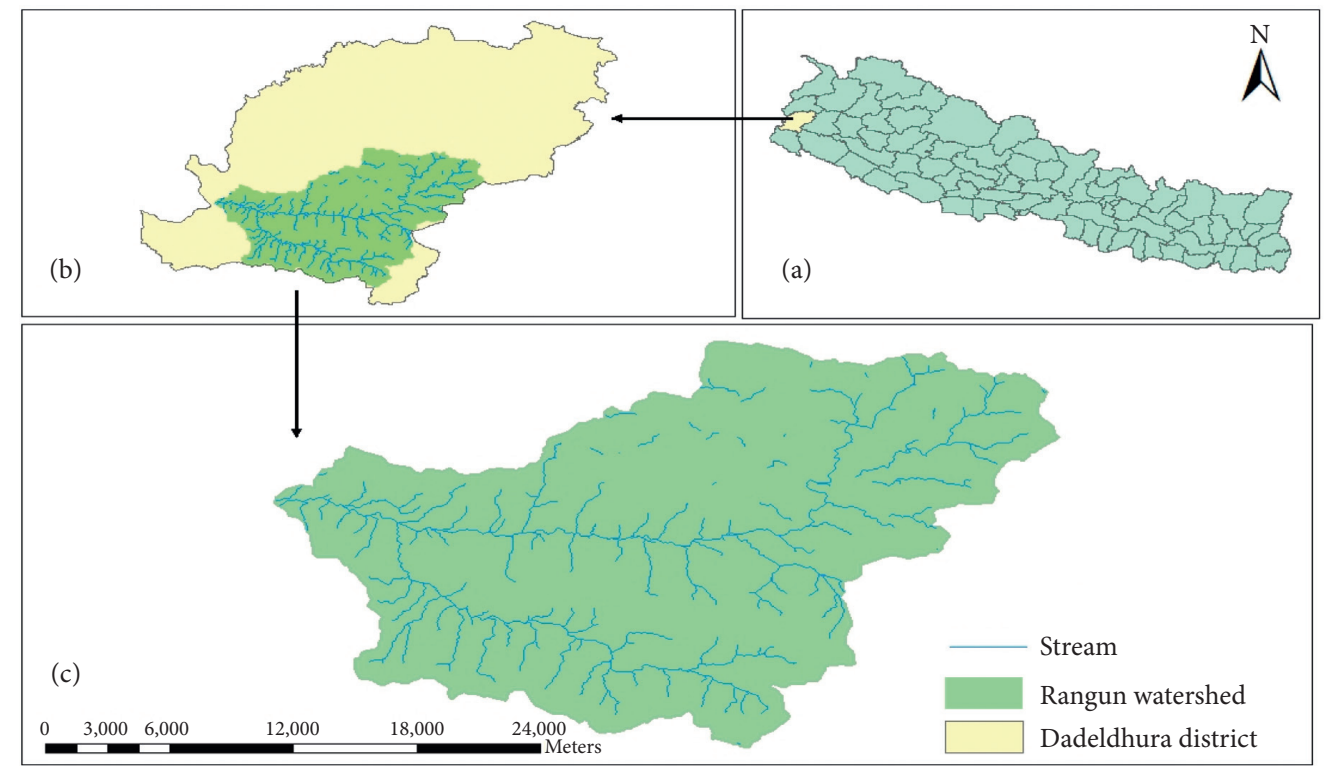

Figure 1: Location map of the study area.

rainfall data for 10 years were taken from the Department of Hydrology and Metrology, Birendranagar, Surkhet district. The slope was derived from DEM developed from whole Nepal DEM map 2010 by using GIS environment. Soil map and soil texture maps were prepared from the FAO Guidelines. Supervised classification and visual interpretation of the land satellite image of March 2019 were carried out for general land use and cover mapping. The data related to rainfall such as number of rainy days, rainfall intensity, and total rainfall were assumed to be similar in the study catchment area. Rainfall intensity was assumed at $10 \mathrm{~mm} \mathrm{~h}^{-1}$ which is erosive for temperate climates because no actual intensity data was found for the study area. Soil detachability index $(K)\left(\mathrm{g} \mathrm{J}^{-1}\right)$ was determined from the literature that corresponds to the soil texture observed in the study catchment.

2.4. RMMF Model Application. The RMMF erosion modeling processes involve the water phase and sediment phase. The water phase mainly comprises prediction of soil detachment by raindrop impact and requires the data related to the intensity of rainfall $\left(I, \mathrm{~mm} \mathrm{~h}^{-1}\right)$, number of rainy days $(R n)$, and average annual rainfall $(R, \mathrm{~mm})$. After developing the different input spatial maps (layers), the rate of soil detachment by raindrop impact $\left(F, \mathrm{~kg} \mathrm{~m}^{-2}\right)$, rate of soil detachment by runoff $\left(H, \mathrm{~kg} \mathrm{~m}^{-2}\right)$, and transport capacity of overland flow (runoff) (TC, $\mathrm{kg} \mathrm{m}^{-2}$ ) are calculated in the ILWIS Academic 3.3 environments as follows:

$$
\begin{aligned}
F & =K \times \mathrm{KE} \times 10^{-3}, \\
H & =Z Q^{1.5} \operatorname{sinmap}(1-\mathrm{GC}) \times 10^{-3}, \\
T C & =C Q^{2} \operatorname{Sinmap} \times 10^{-3},
\end{aligned}
$$

where $F$ is raindrop impact $\left(\mathrm{kg} / \mathrm{m}^{2}\right), K$ is erodibility of the soil $(\mathrm{g} / \mathrm{J}), \mathrm{KE}$ is kinetic energy of the effective rainfall $\left(\mathrm{J} / \mathrm{m}^{2}\right)$, $H$ is soil particle detachment by runoff, $Z$ is resistance of the soil, that is $1 /(0.5 \mathrm{COH}), Q$ is annual runoff $(\mathrm{mm})$, sin map was obtained from slope map of the study area by using the formula SIN $($ DEGGRD) $\times$ slope map, GC is percentage ground cover (0-1), and $c$ is crop management factor.

Finally, total particle detachment $(D=F+H)$ by runoff $(H)$ and raindrop $(F)$ impacts is computed. Total annual soil erosion was calculated by comparing annual detachment $(D)$ to annual transport capacity (TC). The lesser of the two values indicate the annual soil erosion rate [31, 33-35] as shown in Figure 2 and Tables 1 and 2.

2.5. Erosion Risk Assessment. The model estimated soil erosion values were grouped into six soil erosion risk classes based on the range of soil loss values. The soil erosion risk classes are categorized as very low $\left(<5 \mathrm{th}^{-1} \mathrm{yr}^{-1}\right)$, low (5-10 $\left.\mathrm{tha}^{-1} \mathrm{yr}^{-1}\right)$, moderate $\left(10-15 \mathrm{tha}^{-1} \mathrm{yr}^{-1}\right)$, moderately high (15-25 $\left.\mathrm{t} \mathrm{ha}^{-1} \mathrm{yr}^{-1}\right)$, high (25-50 $\left.\mathrm{t} \mathrm{ha}^{-1} \mathrm{yr}^{-1}\right)$, and very high $\left(>50 \mathrm{t} \mathrm{ha}^{-1} \mathrm{yr}^{-1}\right)$. Finally, a soil erosion risk zonation map was generated using operative functions of the RMMF model and in the ILWIS software environment. Soil erosion risk assessment was studied LULC-wise over the whole watershed.

2.6. Field Work. Direct observation for the condition of the soil erosion and land use and land cover was conducted from August to October in 2019. The household survey was carried out by taking $10 \%$ sampling intensity. Information about farm holding size, perception on extent of soil erosion, cropping pattern, agents causing damage to crops, and crop production was collected from households. Altogether 120 HHs from three villages (Sisne, Jogbuda, and Raksoon) were surveyed using a semistructured questionnaire. Cluster sampling which divided each village into low, medium, and high erosion risk was used, for each cluster; systematic sampling was applied for the household survey (every 10th 


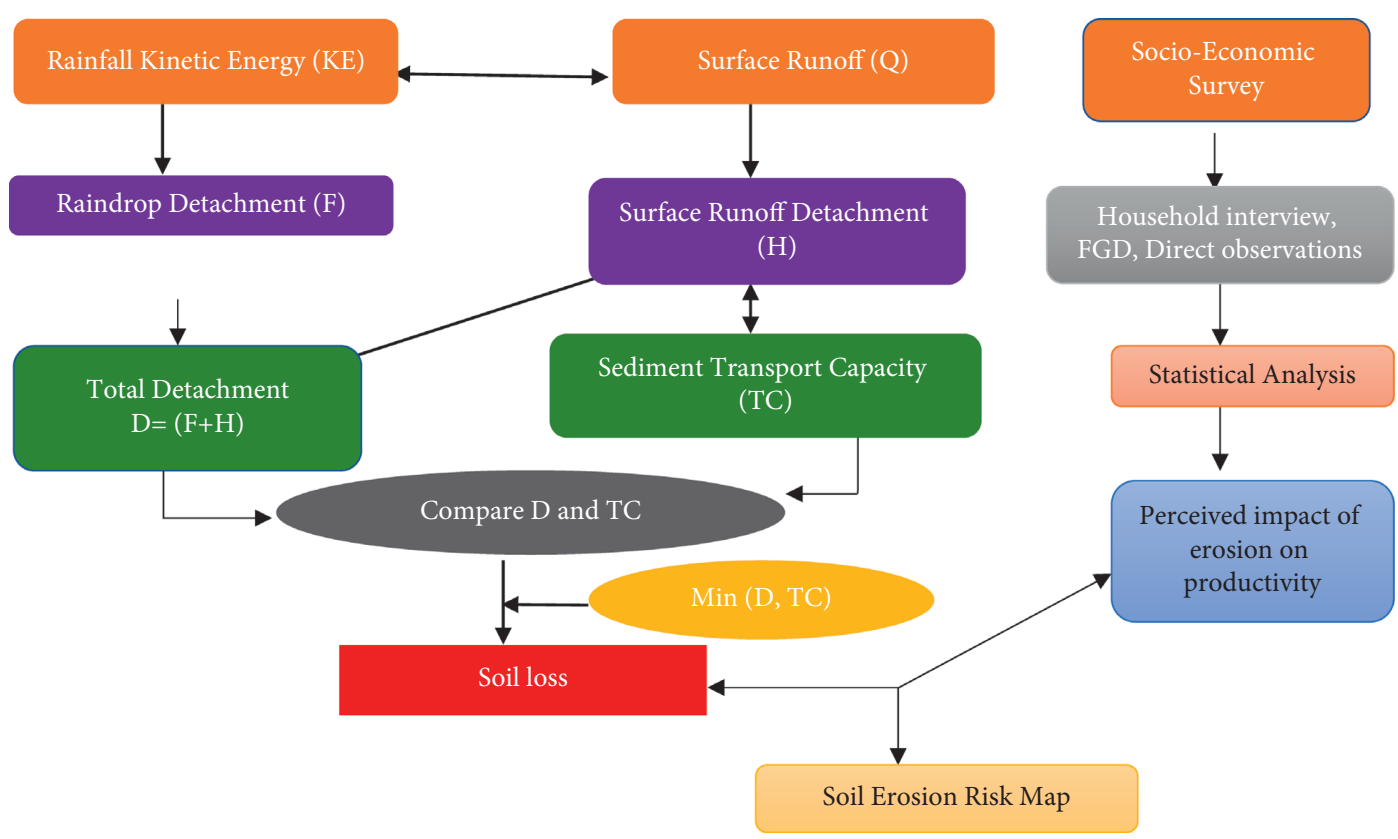

Figure 2: Flowchart of the methodology used for RMMF modeling.

TABle 1: Vegetation parameter for different LULC in the Rangun watershed.

\begin{tabular}{lccccccccc}
\hline S. no. & $\begin{array}{c}\text { Forest/land use } \\
\text { type }\end{array}$ & $A$ & $C$ & $E t / E_{0}$ & CC & GC & PH & EHD \\
\hline 1 & Forest & 0.3 & 0.005 & 0.9 & 0.7 & 0.3 & 14 & 0.18 \\
2 & Agriculture land & 0.25 & 0.03 & 0.67 & 0.5 & 0.5 & 2 & 0.12 \\
3 & Barren land & 0 & 1 & 0.05 & 0 & 0 & 0 & 0.05 \\
\hline
\end{tabular}

$A$ : the percentage of rainfall contributing to permanent interception; $C$ : the crop cover; $E t / E_{0}$ : the ratio of actual to potential evapotranspiration management factor; CC: canopy cover fraction; GC: ground cover; PH: plant height; EHD: effective root depth.

TABLE 2: Soil-related hydrological parameter values for soil texture in the Rangun watershed.

\begin{tabular}{lccccc}
\hline S. no. & Soil type & $\mathrm{MS}(\%)$ & $\mathrm{BD}\left(\mathrm{g} \mathrm{cm}^{-3}\right)$ & $K\left(\mathrm{~g} \mathrm{~J}^{-1}\right)$ & $\mathrm{COH}(\mathrm{kPa})$ \\
\hline 1 & Loam & 0.2 & 1.3 & 0.8 & 3 \\
2 & Sandy loam & 0.28 & 1.2 & 0.7 & 2 \\
3 & Silty loam & 0.25 & 1.3 & 0.9 & 3 \\
\hline
\end{tabular}

MS: soil moisture at field capacity; BD: topsoil bulk density; $\mathrm{COH}$ : cohesion of topsoil; $K$ : soil detachability index.

household). FGD was carried out in each village to identify and verify erosion risk areas and to deliver information about soil and watershed conservation and share ideas to cope with or adopt conservation practices. Moreover, people's perception of the impact of erosion on agricultural productivity was determined through the social surveys.

2.7. Secondary Data. Land use and land cover map was prepared by downloading LANDSAT image 8, 2019 from USGS, Digital Elevation Model was derived for Whole Nepal DEM 2010, and soil map was prepared by FAO Guideline. Detailed rainfall data including the total amount of rainfall, its intensity, and the total number of rainy days of three stations of Dadeldhura district was collected from DHM, Surkhet, to run the model.

\section{Results and Discussion}

3.1. Spatial Distribution of Hydrophysical Parameters Influencing Erosion. Rainfall, slope, vegetation, soil texture, and land use and land cover are the important factors that influence the soil erosion rate and distribution of erosion risk areas. The study showed that the mean annual rainfall and number of rainy days of the study area were 72 and 1336, respectively (Figure 3 ).

The slope of the study area showed that about $63 \%$ of land had steeper slope, while the remaining $37 \%$ of slope made the watershed more prone to the disaster (Figure 3(c)). This indicated that sources of hydrological losses as runoff and sediment yield can be higher on steep areas as compared to flat to gentle slopes. Influence of slope can also be explained by soil texture; that is, silt and clay soils are dominant towards flat areas, whereas coarse texture is dominant in very steep slope of the watershed (Figure 3(b)). Bulk density is higher (up to 1.30) in the steep slope with low vegetation cover and lower (up to 1.20) in the gentle slope or flat area located at foot slope of the watershed (Figure 3(d)). From this figure, it is observed that soil erosion rate is higher in areas with high bulk density. An increase in bulk density affects the air and water circulation, imbalances plant nutrients and routing system, and results in the increase of soil erosion [36]. The soil moisture at field capacity (MS) of the study area was lower in hilly part as compared to the flat area of the watershed (Figure 3(e)).

According to [37], soil moisture at field capacity was lower in topsoil of hilly region. The lowest MS was associated with poor land use and soil management systems. The 


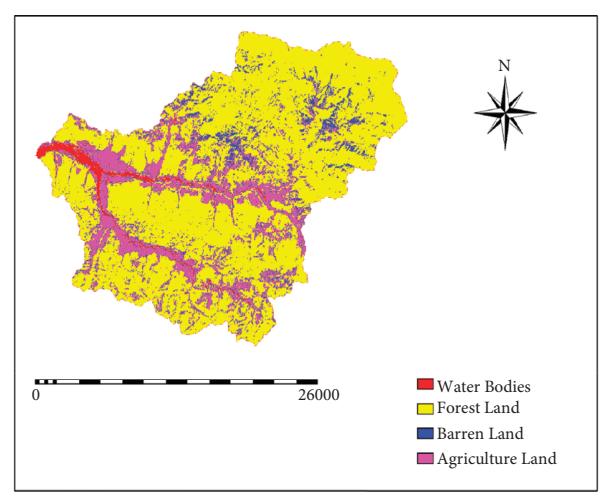

(a)

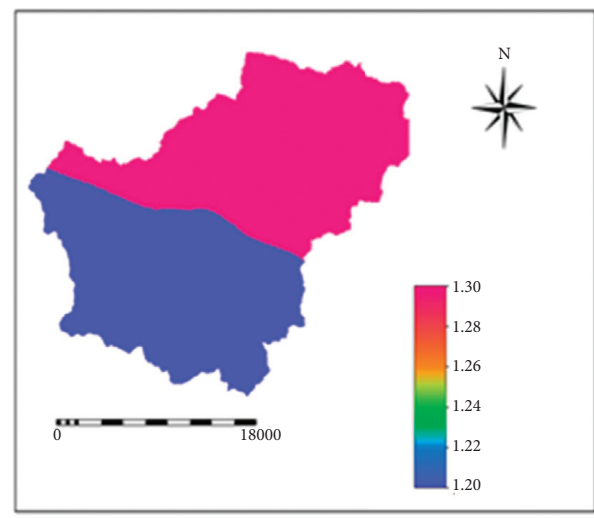

(d)

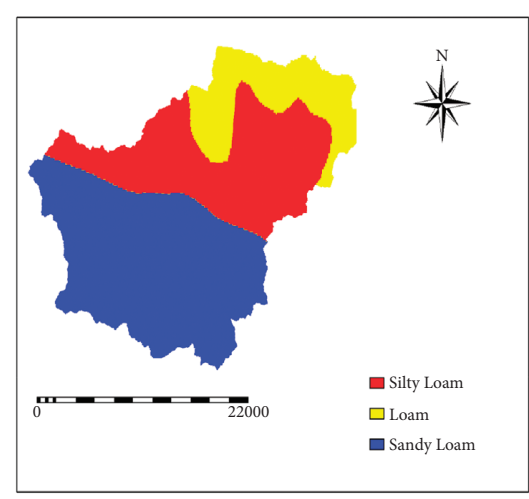

(b)

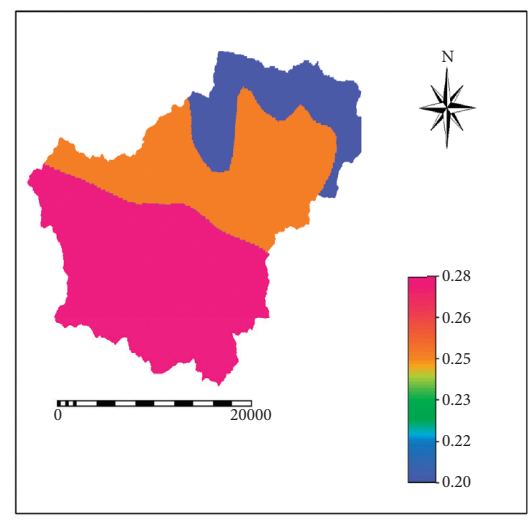

(e)

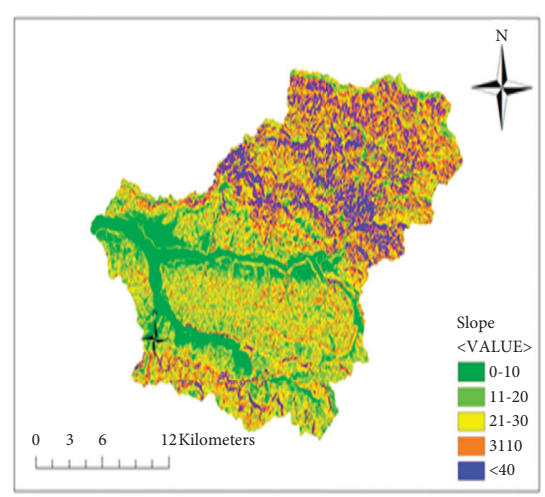

(c)

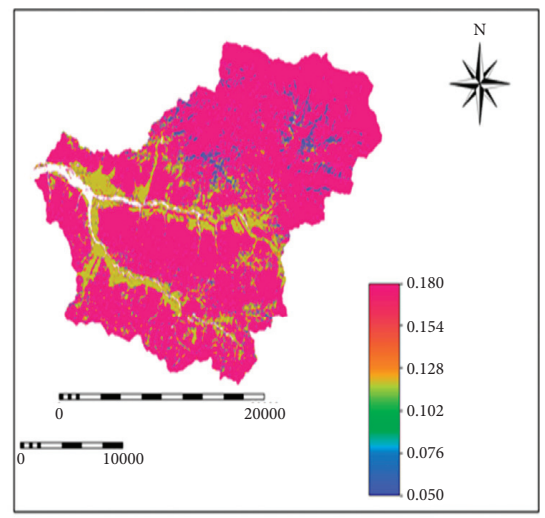

(f)

FIGURE 3: Spatial distribution of parameters influencing the hydrology/erosion of the catchment: (a) LULC map of the study area; (b) soil texture map of the study area; (c) slope map; (d) bulk density; (e) moisture content at field capacity; (f) effective hydrological depth.

effective hydrological depth (EHD) varies from 0.05 to 0.18 meters, where there is a higher value in forest land and there is a medium-to-lower value in agriculture and barren land (Figure 3(f)). Keizer-Vlek et al. [38] stated that vegetation cover with gentle to flat areas had relatively higher EHD and lower EHD in cultivated, marginalized, and degraded land. Thus, the intermediate-to-lower value of EHD indicates the source of high runoff and soil loss as compared to high value of EHD.

The study showed that there was a higher value of $E t / E_{0}$ in forest area, that is, $0.27-0.90$, intermediate value, that is, $0.50-0.72$, corresponding to agriculture or cultivated land, and lower value, that is, $0.06-0.22$, corresponding to degraded barren land (Figure $4(\mathrm{a})$ ). The values of $E t / E_{0}$ are more influenced by cover management factor $(C)$ which ranges from 0.005 to 1 (Figure $4(\mathrm{~b})$ ). The higher crop management in the watershed is expected to have lowered the value of $E t / E_{0}$ and vice versa [37]. Reference [39] argued that crop management maintains the rainfall interception, high rate of evapotranspiration, and runoff infiltration.

Spatial distribution of rainfall interception (Figure 4(c)), ground cover (GC) (Figure 4(d)), cohesion of the soil surface $(\mathrm{COH})$ (Figure 4(e)), and soil detachability index (Figure 4(f)) are important conditions for estimation of soil detachment rate by runoff. The soil detachability by raindrop impact is also influenced by the soil detachability index $(K)$ which showed higher values (up to $0.90 \mathrm{~g} \mathrm{~J}^{-1}$ ) in loam, medium values (up to $0.80 \mathrm{~g} \mathrm{~J}^{-1}$ ) in silty loam, and lower values (up to $0.70 \mathrm{~g} \mathrm{~J}^{-1}$ ) in sandy loam as shown in Figure 4.

3.2. Soil Erosion Status of the Watershed. Soil losses are comparatively lower (less than $3 \mathrm{t} \mathrm{ha}^{-1} \mathrm{yr}^{-1}$ ) under forest land. Annual soil rate is maximum (up to $463 \mathrm{t} \mathrm{ha}^{-1} \mathrm{yr}^{-1}$ ). In the forest area, soil losses varied from 0.01 to $462.59 \mathrm{t} \mathrm{ha}^{-1}$ $\mathrm{yr}^{-1}$ and from 0.01 to $53.73 \mathrm{t} \mathrm{ha}^{-1} \mathrm{yr}^{-1}$ in agriculture land, and, in barren land, it was about 0.01-462.59 $\mathrm{t} \mathrm{ha}^{-1} \mathrm{yr}^{-1}$. The study in [35] on Phewa watershed stated that soil loss rate was lower in forest land, up to $2.6 \mathrm{t} \mathrm{ha}^{-1} \mathrm{yr}^{-1}$ for all periods, medium up to $70 \mathrm{t} \mathrm{ha}^{-1} \mathrm{yr}^{-1}$ in terrace agriculture on steep to very steep slope, and higher in wasteland, up to $661.6 \mathrm{tha}^{-1}$ $\mathrm{yr}^{-1}$. Similarly, [30] presents annual soil losses from forest land which are less than $10 \mathrm{tha}^{-1} \mathrm{yr}^{-1}$ and in agriculture land maximum up to $56 t \mathrm{ha}^{-1} \mathrm{yr}^{-1}$. LULC-wise range and weighted average annual soil losses in the watershed are shown in Table 3. The spatial soil loss map of the study area is shown in Figure 5.

3.3. Soil Erosion Risk Assessment. A total of six erosion classes were made and range was assigned to each risk class. The erosion risk map of the study area is shown in Figure 6. On the basis of the average rate of soil loss, the total area 


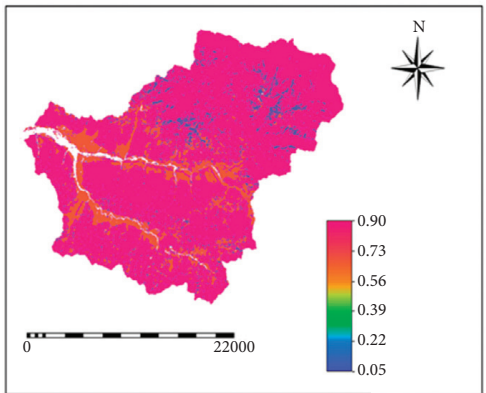

(a)

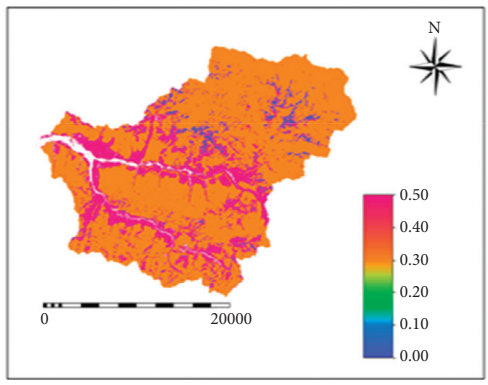

(d)

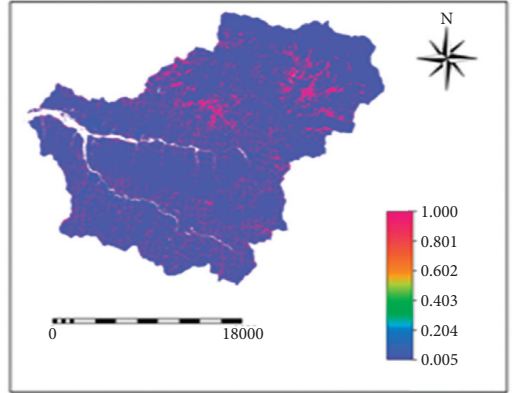

(b)

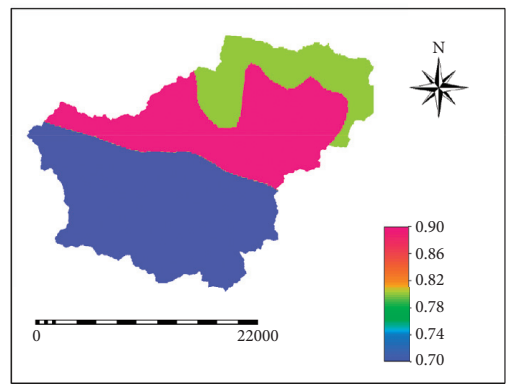

(e)

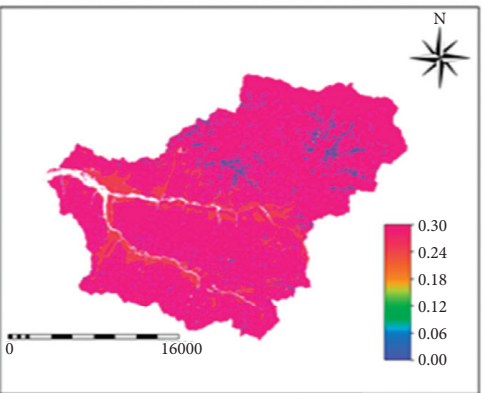

(c)

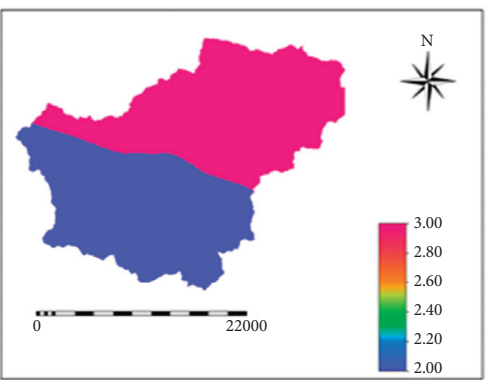

(f)

Figure 4: Spatial distribution of hydrophysical parameters influencing erosion: (a) actual to potential ET; (b) cover crop management; (c) rainfall interception; (d) ground cover; (e) cohesion by surface; (f) soil detachability index.

TABLE 3: LULC-wise annual soil loss in the Rangun watershed.

\begin{tabular}{lccr}
\hline S. no. & LULC class & Soil loss $\left(\mathrm{t} \mathrm{ha}^{-1} \mathrm{yr}^{-1}\right)$ & Wange \\
\hline 1 & Forest & $0.01-2.74$ & 0.39 \\
2 & Agriculture & $0.01-53.73$ & 14.81 \\
3 & Barren & $0.01-462.59$ & 329.21 \\
\hline
\end{tabular}

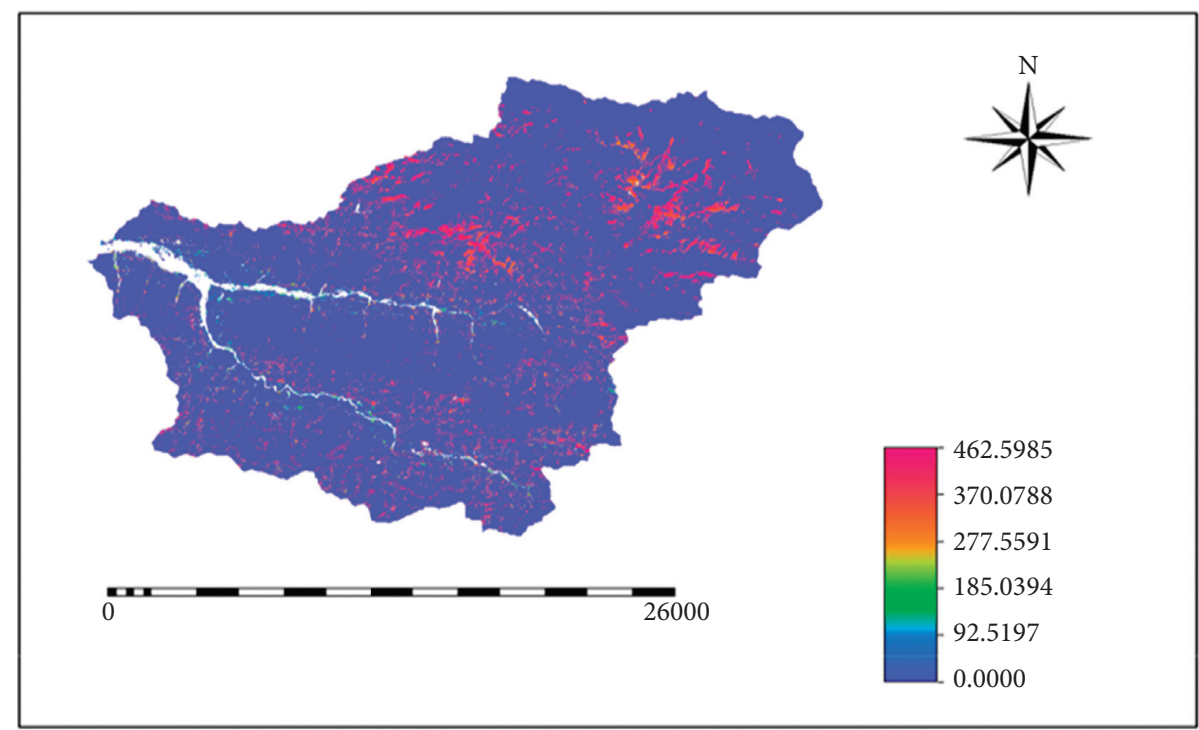

FIGURE 5: Soil loss map of the Rangun watershed. 


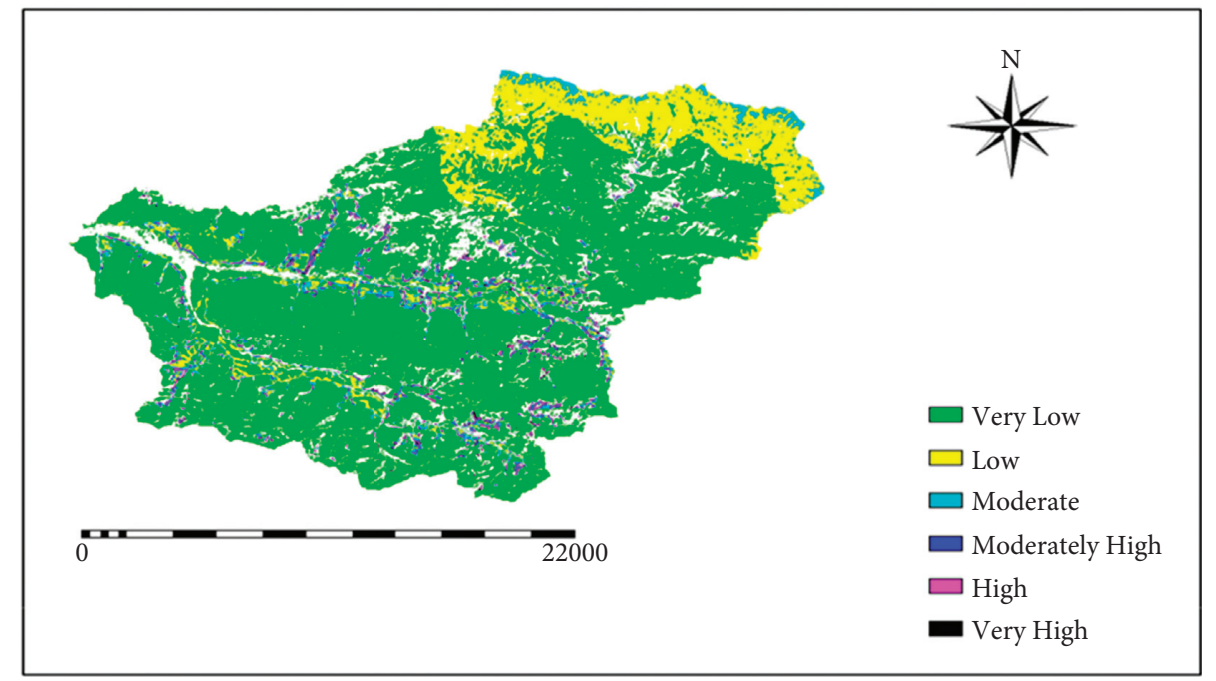

FIGURE 6: Soil erosion risk map of the watershed.

TABle 4: LULC-wise soil erosion risk area based on annual soil loss in the Rangun watershed.

\begin{tabular}{|c|c|c|c|}
\hline S. no. & Erosion risk class & Average soil loss $\left(\mathrm{t} \mathrm{ha}^{-1} \mathrm{yr}^{-1}\right)$ & Area (\%) \\
\hline 1 & Very low & $<5$ & 77.94 \\
\hline 2 & Low & $5-10$ & 14.36 \\
\hline 3 & Moderate & $10-15$ & 3.3 \\
\hline 4 & Moderately high & $15-25$ & 1.66 \\
\hline 5 & High & $25-50$ & 1.47 \\
\hline 6 & Very high & $>50$ & 1.26 \\
\hline & & \multicolumn{2}{|c|}{100} \\
\hline
\end{tabular}

TABle 5: Perceived impact of erosion on agricultural productivity.

\begin{tabular}{lcccc}
\hline Rank & Causes & Mean rank & Friedmann value & df \\
\hline 1 & Topsoil removal & 4.19 & & \\
2 & Gully formation & 3.56 & 48.517 & 4 \\
3 & Lack of irrigation & 2.92 & & $P \leq 0.001$ \\
4 & Quality seed & 2.33 & & \\
5 & Insect and pest attack & 2 & & \\
\hline
\end{tabular}

covered by each erosion risk class is shown in Table 4 . About $92.32 \%$ of the watershed area falls under "very low to low" risk of erosion. Similarly, $4.96 \%$ and $2.73 \%$ of the total watershed area were under "moderate to moderately high" and "high to very high" risk of erosion, respectively (Figure $6)$. In the watershed, forest area contributes high proportion of forest land and agriculture and barren land contribute low proportion. The results also indicate that areas with moderately high to very high risk were located in the north and northwest of the study area, while the areas with very low to low risk were located in the southeast and east of the study area.

3.4. Impact of Soil Erosion on Productivity. The direct impact of soil erosion can be identified by ranking the perception for reducing crop productivity and year-wise trend of volume production from people's perception. Table 5 indicates that the major impacts faced by watershed were topsoil removal and gully formation due to heavy rainfall and increase of drought in summer days. The increasing soil erosion problem washed away top fertile soil and respondent agreed that the topsoil removal (mean rank $=4.19$ ) and gully formation (mean rank $=3.56$ ) were the most significant causes of reducing productivity. People believed that there was different perceived impact responsible for reducing crop productivity which is significantly different at $P<0.05$. The results agreed with $[40,41]$, suggesting that soil erosion hazards occur from the actions that expose the soil to rainfall. Similarly, [42] maintained that removals of fertile soil, development of gully, and increase of drought are the major negative effects of erosion on crop productivity.

An overview of five-year data (from year 2015 to 2019) on total volume production and total cropped area and productivity rate of farmland is shown in Figure 7 . The 


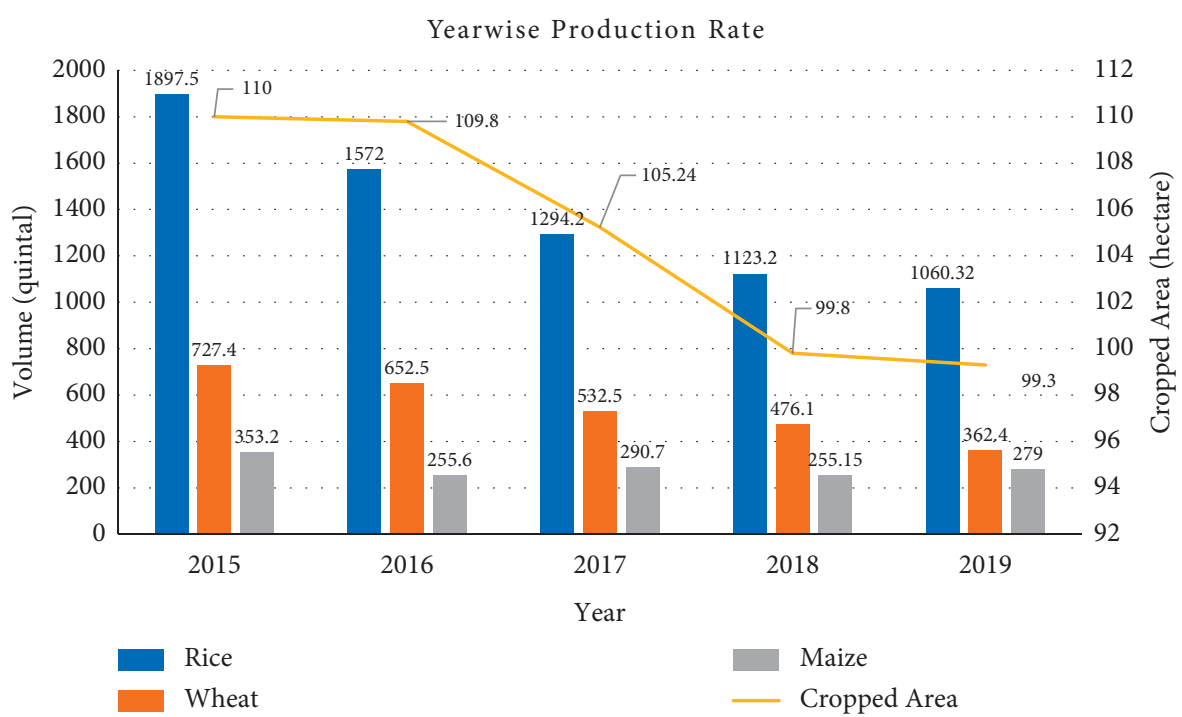

FIGURE 7: Trend of cropped area, production, and productivity in the Rangun watershed.

given figure reveals that cropped area, total volume production, and productivity rate were on decreasing trend. Numerically, cropped area has been reduced with average of 2.96 ha per year. Likewise, total production has been decreased by 317.84 Quintals per year for the last five years, which shows that productivity has been decreased by 2.38 $Q \mathrm{ha}^{-1}\left(0.238 \mathrm{t} \mathrm{ha}^{-1}\right)$ per year. Thus, the evidence suggests that loss of topsoil and gully formation in arable land decrease the productivity rate with decreasing net cropped area. The result agree with [43], pointing out that expansion of land degradation due to erosion in the watershed is a major hindrance for the sustainable agriculture in the region.

\section{Conclusion}

Soil erosion is more pronounced in agriculture and barren land of the watershed. Annual soil losses rate from the forest land was found to be minimum. The study also demonstrated that the model can be modeled in mid-hill region to assess soil erosion risk based on annual soil loss rates in considerable short time and low cost. Spatial soil erosion risk was found to be moderately high to very high (erosion rate $>10 \mathrm{t} \mathrm{ha}^{-1} \mathrm{yr}^{-1}$ ) in steep to very steep slope of agriculture and barren land compared to flat areas and there was low risk in areas covered with forests.

The cropped area total volume production of crops and productivity rate of the watershed have been reduced due to the removal of topsoil and gully formation. According to the finding in the study, the impact of soil erosion in terms of its severity and productivity rate is found to be negatively high. Similarly, the three most significant reasons for reducing agricultural productivity of the watershed are removal of top fertile soil, gully formation in farmland, and increasing doughtiness during summer season. However, soil erosion impact is expressed in the form of negative effect on crop productivity, shortage of grazing land or farmland, and reduced fertility.
4.1. Recommendation. The sources of such higher soil loss rates were identified mainly to be the eroded sites, low soil quality soils, marginal land, overgrazed lands, and monocropping cultivated land system with poor soil management and conservation measures located in the mountainous (northwest) and central landforms of the watershed. Therefore, introducing appropriate site-specific interventions such as agroforestry, agronomic practices, enclosure of degraded lands, and conservation measures based on the model erosion maps produced for the study catchment are suggested to be a practical solution for attaining sustainable environmental management. Bioengineering techniques are important in stabilizing stream banks and reducing landslides in degraded river basins.

There is no single legislative act and/or policy formulated to combat land degradation in Nepal. However, there are numerous sectorial policies and periodical plans of the Nepalese government which have listed soil and land degradation management as a high priority. Department of watershed management of Dadeldhura needs to prepare periodic plans which are more realistic, emphasizing capacity enhancement, local participation, and infrastructure strengthening.

\section{Data Availability}

The data used to support the findings of this study are available from the corresponding author upon request.

\section{Conflicts of Interest}

The authors declare that they have no conflicts of interest.

\section{Acknowledgments}

The authors are grateful to the NORHED-SUNREM Himalaya Project and Ministry of Industry, Tourism, Forest, and Environment of Far-Western Province for providing a 
Research Grant Scheme. Similarly, they provide sincere gratitude to Professor Mr. Krishna Raj Tiwari, PhD (Dean), Assistant Professor Mr. Rajan Subedi, and the staff of IOF for their contributions to accomplish this study. They are thankful to the Sub-Division Forest Office, Aalital RM, and some field experienced local people of the Dadeldhura district for their generous support during the fieldwork.

\section{References}

[1] P. Koirala, S. Thakuri, S. Joshi, and R. Chauhan, "Estimation of soil erosion in Nepal using a RUSLE modeling and geospatial tool," Geosciences, vol. 9, no. 4, p. 147, 2019.

[2] D. P. Shrestha, J. A. Zinck, and E. Van Ranst, "Modelling land degradation in the Nepalese Himalaya," Catena, vol. 57, no. 2, pp. 135-156, 2004.

[3] W. Li, R. Buitenwerf, R. N. Chequín et al., "Complex causes and consequences of rangeland greening in south America-multiple interacting natural and anthropogenic drivers and simultaneous ecosystem degradation and recovery trends," Geography and Sustainability, vol. 1, no. 4, pp. 304-316, 2020.

[4] P. Paudel and G. Kafle, "Assessment and prioritization of community soil and water conservation measures for adaptation to climatic stresses in Makawanpur district of Nepal," Journal of Wetlands Ecology, vol. 6, pp. 44-51, 2012.

[5] M. K. Jha and R. C. Paudel, "Erosion predictions by empirical models in a mountainous watershed in Nepal," Journal of Spatial Hydrology, vol. 10, no. 1, pp. 89-102, 2010.

[6] K. P. Bhandari, J. Aryal, and R. Darnsawasdi, "A geospatial approach to assessing soil erosion in a watershed by integrating socio-economic determinants and the RUSLE model," Natural Hazards, vol. 75, no. 1, pp. 321-342, 2015.

[7] UNEP, Asia Pacific Environment Outlook, United Nations Environment Programme (UNEP)_Environment Assessment Programme for Asia and Pacific, Asian Institute of Technology, Bangkok, Thailand, 1997.

[8] E. Aksoy and M. S. Dirim, "Soil mapping approach in GIS using landsat satellite imagery and DEM data," African Journal of Agricultural Research, vol. 4, no. 11, pp. 1295-1302, 2009.

[9] S. Hacisalihoglu, E. Oktan, and Z. Yucesan, "Predicting soil erosion in oriental spruce (Picea orientalis (L.) link.) stands in eastern black sea region of Turkey," African Journal of Agricultural Research, vol. 5, no. 16, pp. 2200-2214, 2010.

[10] M. Kefi and K. Yoshino, "Evaluation of the economic effects of soil erosion risk on agricultural productivity using remote sensing: case of watershed in Tunisia," The International Archives of the Photogrammetry, Remote Sensing and Spatial Information Sciences, vol. 38, no. 8, p. 930, 2010.

[11] M. Rahman, "A study on exploration of ethnobotanical knowledge of rural community in Bangladesh: basis for biodiversity conservation," International Scholarly Research Notices, vol. 2013, Article ID 369138, 10 pages, 2013.

[12] P. Panagos, G. Standardi, P. Borrelli, E. Lugato, L. Montanarella, and F. Bosello, "Cost of agricultural productivity loss due to soil erosion in the European Union: from direct cost evaluation approaches to the use of macroeconomic models," Land Degradation \& Development, vol. 29, no. 3, pp. 471-484, 2018.

[13] S. J. Scherr, "Soil degradation: a threat to developing-country food security by 2020?" International Food Policy Research Institute, vol. 27, 1999.
[14] R. P. C. Morgan, "A simple approach to soil loss prediction: a revised Morgan-Morgan-Finney model," Catena, vol. 44, no. 4, pp. 305-322, 2001.

[15] D. M. Kagabo, L. Stroosnijder, S. M. Visser, and D. Moore, "Soil erosion, soil fertility and crop yield on slow-forming terraces in the highlands of Buberuka, Rwanda," Soil and Tillage Research, vol. 128, pp. 23-29, 2013.

[16] D. Pimentel, "Soil erosion: a food and environmental threat," Environment, development and sustainability, vol. 8, no. 1, pp. 119-137, 2006.

[17] R. Amundson, A. A. Berhe, J. W. Hopmans, C. Olson, A. E. Sztein, and D. L. Sparks, "Soil and human security in the 21st century," Science, vol. 348, no. 6235, Article ID 1261071, 2015.

[18] Food and Agriculture Organization, Status of the World's Soil Resources (SWSR)-Main Report, Food and Agriculture Organization of the United Nations and Intergovernmental Technical Panel on Soils, Rome, Italy, 2015.

[19] A. R. Graves, J. Morris, L. K. Deeks et al., "The total costs of soil degradation in England and Wales," Ecological Economics, vol. 119, pp. 399-413, 2015.

[20] S. Issaka and M. A. Ashraf, "Impact of soil erosion and degradation on water quality: a review," Geology, Ecology, and Landscapes, vol. 1, no. 1, pp. 1-11, 2017.

[21] B. Prasad, R. K. Jaiswal, and D. H. Tiwari, “Assessment of environmentally stressed areas for soil conservation measures using USPED model," International Journal of Engineering Research, vol. 3, pp. 58-63, 2014.

[22] R. Lal, "Soil erosion impact on agronomic productivity and environment quality," Critical Reviews in Plant Sciences, vol. 17, no. 4, pp. 319-464, 1998.

[23] R. Lal, "Restoring soil quality to mitigate soil degradation," Sustainability, vol. 7, no. 5, pp. 5875-5895, 2015.

[24] C. Fernández, J. A. Vega, and D. C. S. Vieira, "Assessing soil erosion after fire and rehabilitation treatments in NW spain: performance of RUSLE and revised morgan-morgan-finney models," Land Degradation \& Development, vol. 21, no. 1, pp. 58-67, 2010.

[25] R. C. MacCallum, D. T. Wegener, B. N. Uchino, and L. R. Fabrigar, "The problem of equivalent models in applications of covariance structure analysis," Psychological Bulletin, vol. 114, no. 1, pp. 185-199, 1993.

[26] R. Benavidez, B. Jackson, D. Maxwell, and K. Norton, "A review of the (revised) universal soil loss equation ((R)USLE): with a view to increasing its global applicability and improving soil loss estimates," Hydrology and Earth System Sciences, vol. 22, no. 11, pp. 6059-6086, 2018.

[27] A. Bronstert, J.-C. de Araújo, R. J. Batalla et al., "Processbased modelling of erosion, sediment transport and reservoir siltation in mesoscale semi-arid catchments," Journal of Soils and Sediments, vol. 14, no. 12, pp. 2001-2018, 2014.

[28] C. Alewell, P. Borrelli, K. Meusburger, and P. Panagos, "Using the USLE: chances, challenges and limitations of soil erosion modelling," International Soil and Water Conservation Research, vol. 7, no. 3, pp. 203-225, 2019.

[29] N. Efthimiou, "Development and testing of the revised morgan-morgan-finney (RMMF) soil erosion model under different pedological datasets," Hydrological Sciences Journal, vol. 64, no. 9, pp. 1095-1116, 2019.

[30] D. P. Shrestha, "Assessment of soil erosion in the nepalese Himalaya: a case study in likhu khola valley, middle mountain region," Land Husbandry, vol. 2, no. 1, pp. 59-80, 1997. 
[31] R. P. C. Morgan, D. D. V. Morgan, and H. J. Finney, "A predictive model for the assessment of soil erosion risk," Journal of Agricultural Engineering Research, vol. 30, pp. 245-253, 1984.

[32] G. B. Tesfahunegn, L. Tamene, and P. L. Vlek, "Soil erosion prediction using morgan-morgan-finney model in a GIS environment in northern Ethiopia catchment," Applied and Environmental Soil Science, vol. 2014, Article ID 468751, 15 pages, 2014.

[33] L. D. Meyer and W. H. Wischmeier, "Mathematical simulation of the process of soil erosion by water," Transactions of the ASAE, vol. 12, no. 6, pp. 754-0758, 1969.

[34] R. P. C. Morgan, "A simple approach to soil loss prediction: a revised morgan-morgan-finney model," Catena, vol. 44, no. 4, pp. 305-322, 2001.

[35] R. R. Regmi, Land Use Land Cover Change Modeling and Impact Assessment on Soil Erosion Status in Phewa Lake Watershed of Nepal Using Geospatial Tools, Forest Research Institute University, Dehradun, India, 2014.

[36] L. W. Doran, "Soil health and global sustainability: translating science into practice," Agriculture, ecosystems \& environment, vol. 88, no. 2, pp. 119-127, 2002.

[37] P. Behera, K. H. V. Durga Rao, and K. K. Das, "Soil erosion modeling using MMF model-a remote sensing and GIS perspective," Journal of the Indian Society of Remote Sensing, vol. 33, no. 1, pp. 165-176, 2005.

[38] H. E. Keizer-Vlek, P. F. Verdonschot, R. C. Verdonschot, and D. Dekkers, "The contribution of plant uptake to nutrient removal by floating treatment wetlands," Ecological Engineering, vol. 73, pp. 684-690, 2014.

[39] Y. Alaga and G. A. Oluwatosin, "Soil erosion prediction using MMF model on highly dissected hilly terrain of ekiti environs in southwestern Nigeria," International Journal of the Physical Sciences, vol. 4, no. 2, pp. 53-57, 2009.

[40] D. Pimentel, "Soil erosion: a food and environmental threat," Environment, Development and Sustainability, vol. 8, no. 1, pp. 119-137, 2006.

[41] B. Pradhan, A. Chaudhari, J. Adinarayana, and M. F. Buchroithner, "Soil erosion assessment and its correlation with landslide events using remote sensing data and GIS: a case study at Penang Island, Malaysia," Environmental Monitoring and Assessment, vol. 184, no. 2, pp. 715-727, 2012.

[42] I. D. Ighodaro, F. S. Lategan, and S. F. Yusuf, "The impact of soil erosion on agricultural potential and performance of Sheshegu community farmers in the eastern cape of south Africa," Journal of Agricultural Science, vol. 5, no. 5, pp. 140-147, 2013.

[43] H. Kumar and P. Pani, "Effects of soil erosion on agricultural productivity in semi-arid regions: the case of lower Chambal valley," Journal of Rural Development, vol. 32, no. 2, pp. 165-184, 2013. 